\title{
Hard targets
}

Mike Daube

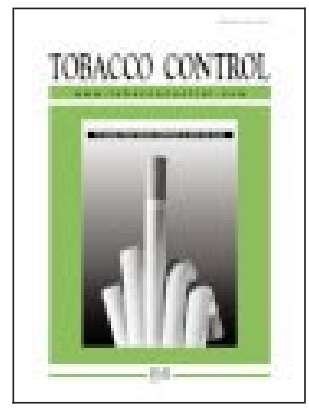

During the 1980s and early 90s Western Australia's relatively well funded, innovative, and aggressive media campaigns attracted international recognition and contributed to a welcome reduction in smoking prevalence. ${ }^{1}$

During the 1990s funding for media declined; cautious governments ensured less forceful advertising; comprehensive legislation (including an ad ban) may in truth have led us into some temporary complacency; and the decline in smoking stalled, with adult prevalence remaining at around $25 \%{ }^{1}$

The Cancer Foundation of Western Australia decided that it was not enough simply to press for governments to spend money. So in early 2000 we established our own "Target 15" tobacco campaign. Why "Target 15"? Because our aim is to reduce adult prevalence to $15 \%$ or less by 2010 .

Our tobacco programme will shortly receive $10 \%$ of Cancer Foundation annual expenditure. This means raising more funds so that other aspects of our work will not suffer. But how can a cancer organisation retain credibility without spending substantial amounts on tobacco control? And the more we spend, the

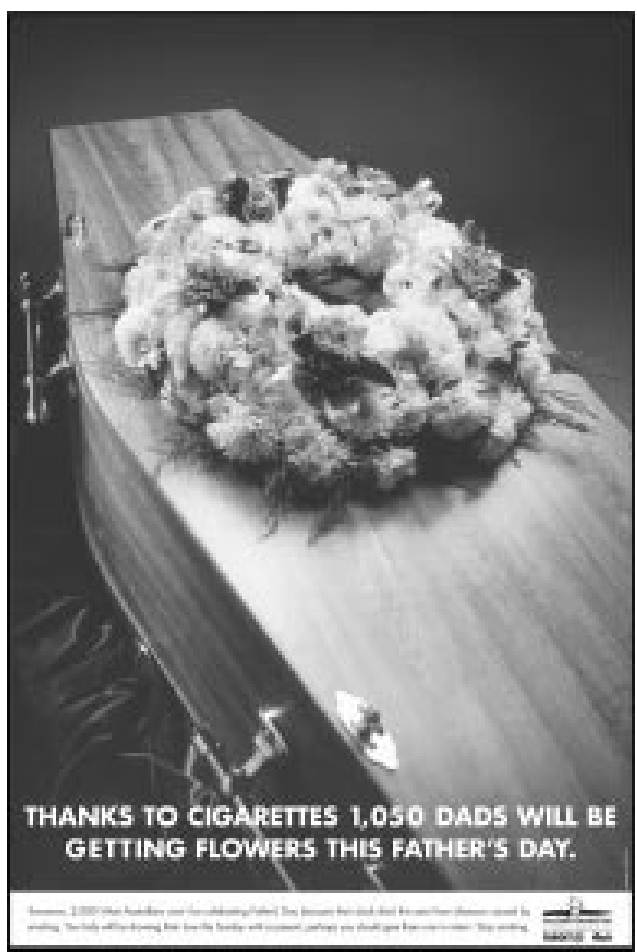

Figure 1 more credible we are in pressing for governments to do the same.

We approached the state government for matching funds, with the caveat that this must not take money away from their own tobacco programme. To their credit, they agreed to provide us with funds-and without any constraints.

Target 15 has focused mainly on TV and radio. We believed that it was time for a return to hard hitting TV ads, and our first media campaign both evaluated superbly and has just won our advertising industry's "Advertisement of the year" award.

But we also wanted to ensure a focus through the press on the magnitude of the problem and the continuing nastiness of the Australian tobacco industry. Advertisements of this kind serve multiple purposes: they affect smokers; they complement our TV and radio campaigns; they have a political impact (important in the light of the industry's lobbying); and the unpaid coverage they attract on all media results in attention worth far more than the cost of an ad.

So we have been running a series of full page ads in the press: all designed to be dramatic,

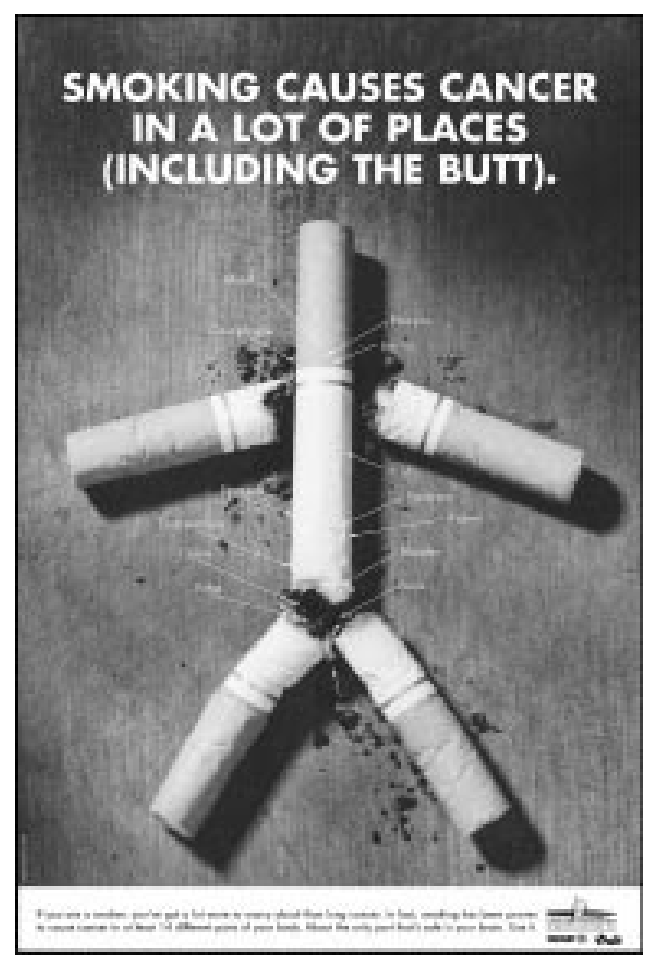

Figure 2 
unashamedly opportunistic, and with an advertising agency revelling in the brief (figs 1 , 2,3 , and 4).
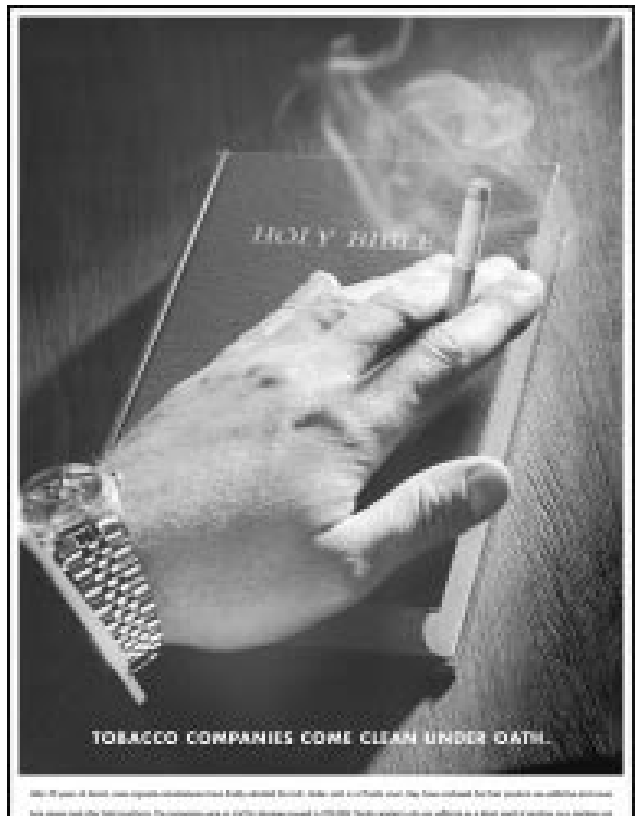
-

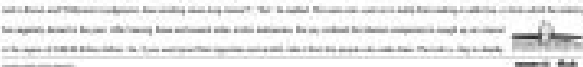

Figure 3

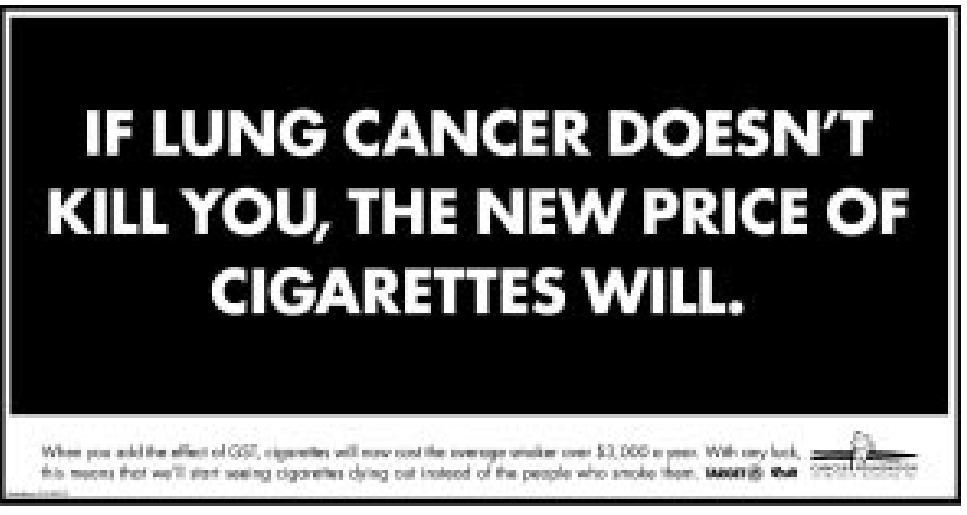

Figure 4
In a country obsessed with illicit drugs, we have shown how tobacco mortality stacks up against heroin. We have used tax increases to encourage quitting. We have explained the background to Target 15 . We have run ads to coincide with occasions such as Father's Day (pointing out how many fathers miss out on Father's Day because they smoked (fig 1)). We have shown graphically that smoking is the cause of at least 14 different cancers-not only lung cancer (fig 2). And we have taken aim at the tobacco companies as the cause of so much avoidable death and misery. We have drawn attention to their lies, their admissions, and their ruthless efforts to mislead smokers, the broader public, and decision makers alike (fig 3).

Do the ads work? No ad in isolation will solve all the world's problems ... But they have indeed generated the complementary media coverage for which we had hoped; they have attracted much complimentary comment from smokers and others in the community; and they have emerged exceptionally well from our market research.

And how times have changed. On 30 September 2000, the 50th anniversary of the seminal $B M F$ paper on smoking and lung cancer by Hill and Doll, ${ }^{2}$ we ran a full page ad about the way the industry has responded to the evidence, headed "Commemorating 50 years of lies and deceit". We noted that smoking had claimed 827000 Australian lives since the initial Hill and Doll paper accused the companies of breaking just about all of the Ten Commandments (with the possible exception of that pesky one about coveting thy neighbour's ox) - and heard not a squeak of complaint from any of the companies or their lawyers. It is of course all true - and the more smokers hear it, the more they will want to quit. We have every intention of helping them, and of having some fun along the way.

1 Health Department of Western Australia. Smoking and health in Western Australia 1998 resource book. Development and Support Branch, Public Health Division, Health Department of Western Australia, 1998.

2 Doll R, Hill AB. Smoking and carcinoma of the lung. BMF 1950;ii:739. 